\title{
Analisis kebutuhan media pembelajaran pada materi evolusi untuk peserta didik SMA kelas XII
}

\author{
Mutiah Putri Kuvita Rani ${ }^{1 *}$, Hendro Kusumo Eko Prasetyo Moro ${ }^{2}$ \\ Pendidikan Biologi, Fakultas Keguruan dan Ilmu Pendidikan, Universitas Ahmad Dahlan \\ Jl. Jendral Ahmad Yani (Ringroad Selatan) Tamanan, Banguntapan, Bantul \\ Daerah Istimewa Yogyakarta 55191 \\ 1 putri.kuvitarani@gmail.com*; morosmart@yahoo.com \\ *korespondensi penulis
}

\begin{abstract}
Abstrak
Kurikulum 2013 diimplementasikan dengan pendekatan ilmiah memberikan tantangan tersendiri bagi guru untuk meningkatkan kualitas pembelajaran peserta didik. Penggunaan media pembelajaran sangat diperlukan dalam pembelajaran melihat dari fungsinya sebagai penyampaian informasi. Apalagi setelah dicanangkannya kurikulum 2013 yang menggunakan pendekatan ilmiah mencakup komponen: mengamati, menanya, mencoba, menalar, mencipta, mengkomunikasikan. Peran media pembelajaran menjadi komponen yang harus ada demi terlaksananya pembelajaran yang aktif dan efektif. Penelitian ini merupakan penelitian deskriptif menggunakan angket dan wawancara. Objek penelitian adalah peserta didik kelas XII SMA N 1 Sumber Lawang dan MA Sunan Pandanaran sejumlah 82 peserta didik. Narasumber adalah guru biologi dan guru agama di sekolah yang sama. Hasil penelitian ini diperoleh beberapa hal yaitu: 1) Kesulitan peserta didik dalam memahami materi evolusi. 2) Peserta didik menginginkan media yang lebih inovatif dan menarik untuk memahami materi evolusi. 3) Model pembelajaran evolusi hanya menerapkan metode diskusi dan presentasi. 4) Pandangan tentang evolusi masih terpatri bahwa dengan mempelajari evolusi sama saja mempercayai manusia itu berasal dari kera sekaligus menentang ajaran agama islam. Kesimpulannya peserta didik kelas XII dari SMA N 1 Sumber Lawang dan MA Sunan Pandanaran memerlukan media cetak yang inovatif dan menarik untuk materi evolusi sebagai pendamping metode pembelajaran diskusi dan ceramah.
\end{abstract}

Kata kunci: analisis, kebutuhan media pembelajaran, materi evolusi, peserta didik kelas XII.

\section{Abstract}

The 2013 Curriculum was implemented with a scientific approach make teacher more challenged to improve the quality of students learning. The use of media learning is indispensable in learning to see its function as information delivery. Especially after the 2013 curriculum has been launched which uses a scientific approach includes components: observing, asking, trying, reasoning, inventing, communicating. The role of Media Learning becomes a component that must exist in order to implement active and effective learning. The research object are 81 students grade XII of SMA N 1 Sumber Lawang and MA Sunan Pandanaran. The speaker is a biology teacher and a religious teacher in the same school. The result of this research were obtained several things: 1) Students' difficulties in understanding the material evolution. 2) Students want a more innovative and engaging medium to understand evolutionary material 3) The evolutionary learning model applies by discussion and presentation 4) The view of evolution is still in the knowledge that by studying evolution, 
believing the human being is from apes and also against the teachings of Islam. Conclusion, students of Grade XII SMA N 1 Sumber Lawang and MA Sunan Pandanaran need innovative and interesting printed media for evolution material as a companion to the method of learning discussion and lecture.

Keywords: Analysis, media, learning and evolution, class XII students.

\section{PENDAHULUAN}

Implementasi Kurikulum 2013 dengan pendekatan ilmiah memberikan tantangan tersendiri bagi guru untuk meningkatkan kualitas pembelajaran peserta didik sehingga peserta didik dapat termotivasi untuk belajar dengan menggunakan pendekatan ilmiah mencakup komponen: mengamati, menanya, mencoba, menalar, mencipta, mengkomunikasikan.

Salah satu materi yang diajarkan untuk Sekolah Menengah Atas (SMA) kelas XII adalah evolusi. Kompetensi inti di dalam materi evolusi biologi segi kognitif mencakup peserta didik diharapkan dapat menjelaskan teori, prinsip dan mekanisme tentang evolusi dan menghubungkan pandangan terkini dari para ahli terkait spesiasi. Sementara dalam psikomotoriknya peserta didik diharapkan dapat menyajikan karya ilmiah terhadap gagasan baru tentang kemungkinan-kemungkinan pandangan evolusi berdasarkan pemahaman yang dimilikinya. Kompetensi yang ditargetkan pada materi evolusi tertuang dalam Peraturan Kementerian Pendidikan dan Kebudayaan tahun 2016 nomor 24 lampiran 7 kelas XII.

Materi evolusi termasuk kedalam objek yang dipelajari pada mata pelajaran biologi. Biologi merupakan salah satu ilmu pengetahuan yang mempelajari makhluk hidup dan kehidupannya dari berbagai aspek persoalan dan tingkat organisasinya. Biologi berkaitan dengan cara mencari tahu dan memahami tentang alam secara sistematis, sehingga biologi bukan hanya penguasaan kumpulan pengetahuan yang berupa fakta-fakta, konsep-konsep, dan prinsip-prinsip saja tetapi juga merupakan suatu proses penemuan. Oleh karena itu, pendidikan biologi diharapkan dapat menjadi wahana bagi siswa untuk mempelajari dirinya sendiri dan alam sekitarnya (Depdiknas, 2003: 6).

Melihat kembali karakteristik mata pelajaran biologi yaitu mempelajari tentang makhluk hidup dan kehidupannya dan menjadi wahana bagi siswa untuk mempelajari dirinya sendiri dan alam sekitarnya. Agar terselenggaranya pembelajaran biologi menurut Carin \& Sund (1990) dalam Sudarisman (2015: 32) hendaknya mengandung 6 unsur yaitu: 1) melibatkan peserta didik secara aktif dalam serangkaian proses ilmiah; 2) pembelajaran yang mendorong rasa ingin tahu siswa; 3) pembelajaran yang dapat mengakomodasi peserta didik tentang: konten biologi (dalam penelitian ini tentang teori, prinsip, mekanisme, dan 
pandangan terkini terkait evolusi); 4) pembelajaran yang memungkinkan peserta didik dapat membangun pengetahuannya melalui pengalamannya secara mandiri; 5) menggunakan sains untuk memecahkan masalah sehari-hari yang ada di masyarakat; 6) kebenaran dalam sains tidak absolut melainkan bersifat tentatif.

Karakteristik perkembangan peserta didik jenjang sekolah menengah atas berdasarkan tingkatan perkembangan kognitif Piaget siswa dalam rentang usia 11 tahun sampai dewasa ada ditaraf perkembangan operasional formal. Dalam tahapan perkembangan operasional formal siswa memiliki pemikiran abstrak dan murni simbolis bisa dilakukan tanpa kehadiran benda konkrit dan masalah-masalah dapat dipecahkan melalui penggunaan eksperimantal sistematis (Suparno, 2001). Dengan begitu penemenuhan kebutuhan media pembelajaran hendaknya menyesuaikan dengan perkembangan peserta didik yang sudah bisa memecahkan permasalahan secara eksperimental dan sistematis.

Media berasal dari bahasa Latin yang merupakan bentuk jamak dari kata medium secara harfiah berarti perantara atau pengantar. Menurut Asosiasi Pendidikan Nasional (National Education Association/ NEA) media adalah bentuk-bentuk komunikasi baik tercetak maupun audiovisual serta peralatannya. Media hendaknya dapat dimanipulasi, dilihat, didengar, dibaca (Sadiman 2011, 7). Dari pengertian media tersebut dapat disimpulkan media merupakan alat bantu dalam proses belajar mengajar yang mengandug materi intruksional dipergunakan untuk merangsang pikiran, perasaan, perhatian, dan kemampuan belajar sehingga dapat mendorong terjadinya proses berpikir pada peserta didik.

\section{METODE}

Penelitian ini merupakan penelitian deskriptif dengan dengan menggunakan angket dan wawancara. Objek penelitian adalah 82 peserta didik kelas XII SMA N 1 Sumber Lawang yang berlokasi di Jl. Solo-Purwodadi No. Km 27, Kebayanan III, Pendem, Kec. Sumberlawang, Kabupaten Sragen, Jawa Tengah dan MA Sunan Pandanaran yang berlokasi di Turen, Sardonoharjo, Kec. Ngaglik, Kabupaten Sleman, Daerah Istimewa Yogyakarta. Narasumber adalah guru biologi dan guru agama di sekolah yang sama.

Penelitian deskriptif adalah suatu bentuk penelitian unuk mendeskripsikan atau menggambarkan fenomena-fenomena yang ada, baik yang bersifat alami atau rekayasa manusia. Penelitian deskriptif dapat juga ditujukan untuk mengadakan kajian yang bersifat kualitatif (Sukmadinata, 2012). Penelitian yang dilakukan tidak memberikan perlakuan, 
manipulasi atau pengubahan pada variabel-variabe bebas tapi menggambarkan suatu kondisi apa adanya terhadap peserta didik.

Angket atau kuesioner merupakan suatu teknik atau cara pengumpulan data secara tidak langsung. Instrumen pengumpulan data juga disebut angket yang berisi sejumlah pertanyaan yang harus dijwab oleh responden. Bentuk pertanyaan bisa terbuka dan tertutup (Sukmadinata, 2005). Angket yang digunakan dalam penelitian ini divalidasi menggunakan judgement expert mencakup lima pertanyaan tertutup dan satu pertanyaan terbuka. Pertanyaan tertutup dengan dua pilihan jawaban "ya" atau "tidak" untuk mengetahui keadaan peserta didik terhadap kebutuhan media pembelajaran, sementara pertanyaan terbuka untuk mengetahui alasan secara deskriptif terhadap jawaban dari pernyataan tersebut. Penyebaran angket di SMA N 1 Sumber Lawang dilakukan pada tanggal 26 Juli 2018 sementara pada MA Sunan Pandanaran 13 Januari 2019.

Wawancara merupakan salah satu bentuk teknik pengumpulan data yang banyak digunakan dalam penelitian deskriptif kualitatif dan dikatakan sebagai teknik pengumpulan data utama (Sukmadinata, 2005). Dalam pelaksanaan penelitian ini pertanyaan tentang pandangan materi evolusi dari sudut pandang mata pelajaran yang diampu dan pelaksanaan pembelajaran evolusi yang dilakukan di dalam kelas. Pertanyaan ditujukan kepada dua guru di MA Sunan Pandanaran diantaranya satu guru pendidikan agama islam dan dua guru biologi.

\section{HASIL DAN PEMBAHASAN}

Hasil dari analisis angket kebutuhan peserta didik terhadap media pembelajaran yang diambil di dua sekolah yaitu SMA N 1 Sumber Lawang dengan sampel 41 dari 143 peserta kelas XII dan MA Sunan Pandanaran dengan sampel 41 dari 110 peserta didik kelas XII. Rata-rata peserta didik mengetahui evolusi, peserta didik mengalami kesulitan dalam pembelajaran terutama pada peserta didik di MA Sunan Pandanaran dan hampir keseluruhan peserta didik membutuhkan media pembelajaran, sementara untuk jenis media pembelajaran jika dibandingkan kedua jenis media cetak dan noncetak paling banyak keinginan jenis media pembelajaran cetak. 


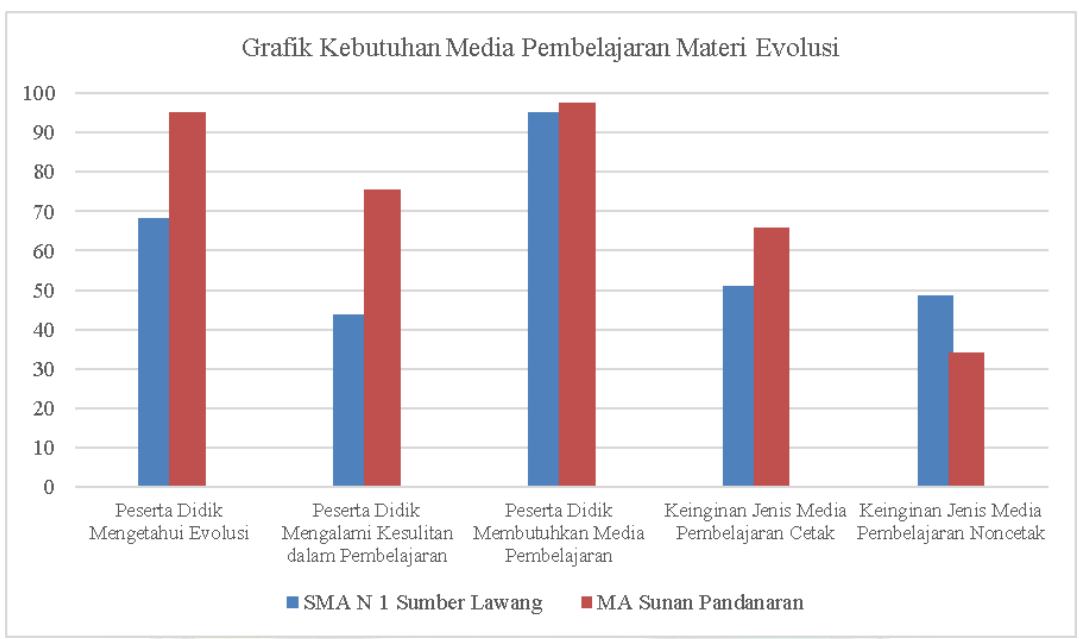

Gambar 1. Grafik kebutuhan media pembelajaran materi evolusi

Berdasarkan grafik di atas walaupun peserta didik menyatakan mengetahui apa itu evolusi setelah diidentifikasi jawaban mereka masih sedikit yang menjabarkan evolusi dalam segi teori, prinsip, dan mekanisme evolusi sesuai dengan sub materi yang terdapat pada kompetensi dasar bab evolusi.
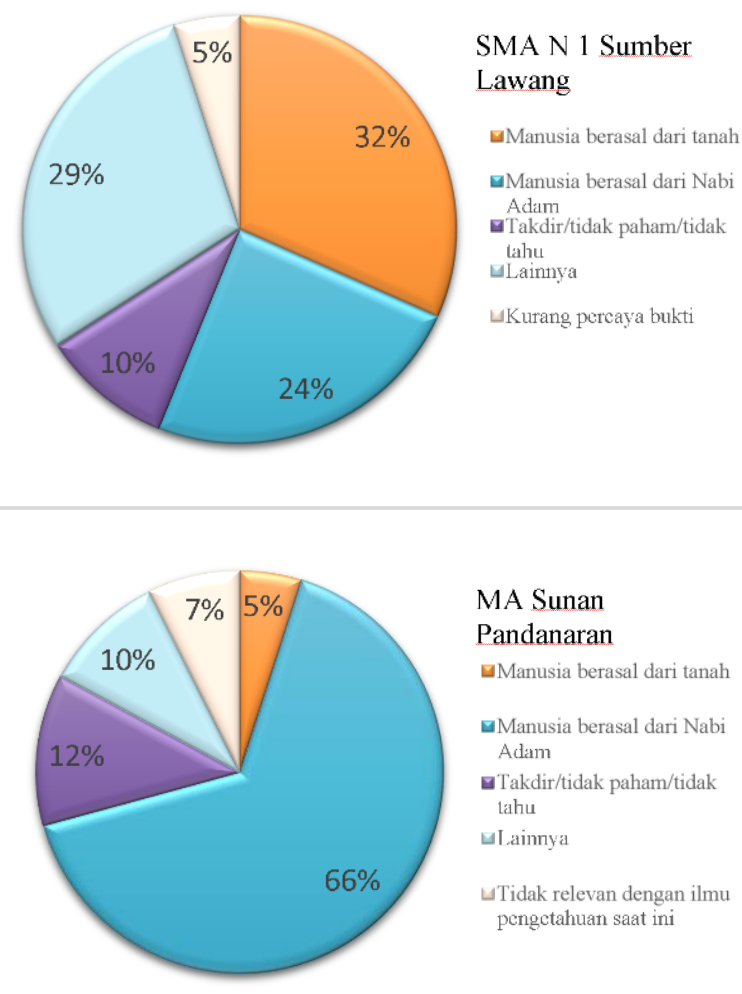

Gambar 2. Diagram respon peserta didik terhadap Teori Evolusi 
Pada diagram di atas menunjukkan bahwa alasan yang diungkapkan peserta didik lebih banyak menyebutkan manusia berasal dari Nabi Adam. Hal ini diperkuat dengan identifikasi jawaban yang dituliskan pada angket terbuka oleh peserta didik dan wawancara yang telah dilakukan. Berdasarkan identifikasi tersebut maka kurang kuatnya konsep materi dapat diindikasikan menjadi penyebab lemahnya pemahaman peserta didik terkait pemahaman keseluruhan materi evolusi yang mencakup teori, prinsip, dan mekanisme evolusi.

Berdasarkan wawancara dengan $\mathrm{Bu}$ Anik Indah Jumini S.Pd. guru biologi yang mengampu kelas XII di Madrasah Aliyah Sunan Pandanaran selama ini beliau dalam pembelajaran evolusi menerapkan metode diskusi dengan diakhiri satu persatu kelompok mempresentasikan hasil diskusinya kedepan kelas. Beliau berpendapat jika menggunakan media pembelajaran dimana sekolah memiliki dukungan terhadap media tersebut akan lebih memahamkan peserta didik sehingga tujuan pembelajaran sangat bisa tercapai. Masih banyaknya peserta didik yang merasa kesulitan dalam memahami materi evolusi dan keinginan media pembelajaran yang lebih inovatif, maka pengembangan media diharapkan dapat membantu proses belajar lebih mudah. Menurut beliau materi evolusi adalah materi biologi yang paling abstrak karena kita tidak mengalami semua peristiwa dan kejadiannya berlangsung dari jaman ke jaman, apalagi teori yang dikemukakan banyak yang tidak bisa teruji secara ilmiah hanya pendapat dari para tokoh saja.

Hasil dari proses wawancara peneliti mencari sudut pandang materi evolusi biologi dari sudut pandang guru agama dengan cara mewawancara guru pendidikan agama islam ibu Tsalis S.Pd. dari Madrasah Aliyah Sunan Pandanaran. Beliau berpendapat bahwa teori evolusi jika dipandang dari agama islam sangat bertolak belakang. Karena sejatinya manusia pertama ialah Adam dan Hawa. Manusia diciptakan dari tanah. Sesuai dengan yang tertuang dalam Q.S Al-Hijr ayat 28. Dengan ini pandangan tentang evolusi masih terpatri bahwa dengan mempelajari evolusi sama saja mempercayai manusia itu berasal dari kera sekaligus menentang ajaran agama islam.

\section{SIMPULAN}

Berdasarkan uraian hasil dapat disimpulkan bahwa peningkatan pemahaman peserta didik terhadap materi evolusi yaitu materi dianggap bertolak belakang dengan nilai agama dan dibutuhkan media yang lebih inovatif dan menarik guna mempermudah pemahaman konsep oleh peserta didik. 


\section{REFERENSI}

Kurikulum, P., \& Depdiknas, B. 2003. Standar Kompetensi Mata Pelajaran Kimia SMA dan MA. Jakarta: Balitbang Depdiknas.

Sadiman, Arief, dkk. 2011. Media Pendidikan: Pengertian, Pengembangan, dan Pemanfaatannya. Ed. 1-15. Jakarta: Rajagrafindao Persada.

Sudarisman, S. 2015. Memahami hakikat dan karakteristik pembelajaran biologi dalam upaya menjawab tantangan abad 21 serta optimalisasi implementasi kurikulum 2013. Florea: Jurnal Biologi dan Pembelajarannya, 2(1).

Sukmadinata, S. N. 2005. Metode Penelitian Pendidikan. Bandung: PT Remaja Rosdakarya. Suparno, P. 2001. Teori Perkembangan Kognitif Jean Piaget. Jogjakarta: Kanisius. 